\title{
A busca por legitimação na cultura homeopática'
}

Lenin Bicudo Bárbara*

https://orcid.org/0000-0002-3002-8800

Introdução

O debate recente sobre o uso da cloroquina no tratamento da Covid-19 reacendeu a velha questão: o que fazer quando uma prática médica não reconhecida pela comunidade científica é legitimada por representantes do poder público?

Não é fácil saber se um medicamento funciona ou não. A experiência pessoal leva com frequência a erros: melhorar após tomar um medicamento não implica melhorar por causa dele. A crença na eficácia das sangrias, que perdurou por séculos, baseava-se, em parte, nesse tipo de erro de atribuição causal. Hoje, graças a ensaios clínicos controlados e randomizados, e a metanálises, podemos chegar a conclusões mais confiáveis acerca da eficácia dos recursos terapêuticos de que dispomos. Mas tais ensaios podem ser custosos e demorados; e entender o resultado de uma metanálise exige conhecimento especializado de estatística, que está fora do alcance do leitor leigo, e mesmo de muitos médicos.

Esperamos, porém, que ao menos as políticas públicas na área de saúde levem em conta a melhor evidência científica disponível; que tenhamos bons motivos para crer

Universidade de São Paulo, São Paulo, Brasil.

1. Este artigo é um desdobramento de minha pesquisa de doutorado, realizada com apoio da Fapesp (número 2013/23766-9); e a reelaboração do material da pesquisa foi possível graças à bolsa de pós-doutorado da Capes (n. 88887.363825/2019-00). Agradeço à Fapesp e à Capes por financiarem a pesquisa; e aos pareceristas anônimos da Tempo Social, pelas sugestóes de melhoria do artigo. 
que os recursos terapêuticos bancados com dinheiro público são seguros e eficazes. O caso da cloroquina mostra que tal expectativa é, na prática, muitas vezes frustrada.

Mas essa não é a primeira, nem será a última iteração da tensão entre a legitimação científica e a pública do conhecimento médico. Neste artigo, trato de um caso especial da mesma tensão básica: o da homeopatia.

Recorte: a vida intelectual da homeopatia

\section{Breve histórico}

A homeopatia é uma doutrina médica criada na virada do século XVIII para o XIX, pelo médico alemão Samuel Hahnemann (1755-1843). A doutrina gira em torno da "lei dos semelhantes", segundo a qual uma substância capaz de produzir um conjunto de sintomas x em uma pessoa saudável seria capaz de curar uma pessoa doente, caso (1) seus sintomas sejam semelhantes a x, e caso (2) tal substância seja submetida à farmacotécnica homeopática, que envolve sua agitação e diluição em série.

Hoje, estamos em condições de saber que os preparados homeopáticos, se prescritos e produzidos conforme as regras da homeopatia, não possuem nenhum efeito terapêutico específico, ao contrário do que alegam os homeopatas. Vários caminhos diferentes levam a tal conclusão. Sabemos que o preparado homeopático que chega ao paciente via de regra não contém princípio ativo; é puro excipiente inerte, sendo o excipiente mais comum a lactose, ou açúcar de leite. Como reconhecem os farmacêuticos homeopatas, nenhuma análise química conhecida é capaz de distinguir dois preparados homeopáticos feitos a partir de substâncias diferentes, como é o caso, digamos, da arnica montana $30 \mathrm{cH}$ e do aurum metallicum $30 \mathrm{CH}$ - feitos este a partir do ouro, e aquele, da arnica. Isso porque a farmacotécnica homeopática dilui a substância inicial a ponto de não deixar nenhum traço dela no produto final, ingerido pelo paciente. Por isso, não é de surpreender que a mais criteriosa metanálise que investigou a eficácia clínica da homeopatia conclua que ela não tem efeitos terapêuticos além do placebo (Shang et al., 2005).

Ao contrário de outras doutrinas médicas que fizeram moda na Europa na virada do século XVIII para o XIX - como o mesmerismo e o brownismo -, a homeopatia segue sendo praticada. Enquanto, nesse ínterim, a medicina convencional mudou drasticamente, a homeopatia permanece essencialmente a mesma. Sua legitimidade como prática médica é, por isso, amiúde objeto de controvérsias públicas acaloradas.

Particularmente controversa é sua oferta no sistema público de saúde. Nos últimos anos, vários países passaram a restringir gastos públicos com homeopatia. No Reino Unido, o serviço de saúde britânico (NHS) anunciou, em novembro de 2017, que 
deixaria de financiar o tratamento com homeopatia. Na França, em julho de 2019, as autoridades sanitárias anunciaram decisão similar, implementada aos poucos, e em pleno vigor desde janeiro de 2021.

O Brasil é uma exceção notável. Desde 1980, o Conselho Federal de Medicina (CFM) reconhece a homeopatia como "especialidade médica" - a mesma categoria que abarca especialidades incontroversas como pediatria, cardiologia e medicina do trabalho. Tal reconhecimento foi consagrado pela Resolução 1000 do CFM. Ele resulta, em parte, do lobby dos "generais da homeopatia" - médicos homeopatas com formação militar e de alta patente - durante a ditadura; e, em parte, da popularidade que a doutrina desfrutou na sociedade civil nos anos 1970, na esteira do movimento contracultural (Luz, 1996, pp. 290 et seq.). Portanto, quando o sus é criado, a homeopatia já é classificada como especialidade médica. Hoje, várias cidades do Brasil oferecem atendimento homeopático pelo sUs, apesar das críticas da comunidade científica.

A história da homeopatia no Brasil e no mundo é marcada por altos e baixos. No Brasil, aonde chega em 1840, seus anos de ouro foram as três primeiras décadas do século XX, época em que foram criados um hospital e uma faculdade de homeopatia, no Rio de Janeiro. A partir dos anos 1930, ela perde novamente espaço, para renascer nos anos 1970. Por isso, os homeopatas sabem que seu reconhecimento por parte da comunidade médica é sempre precário.

Criticados pela comunidade científica e também por parte da comunidade médica, os homeopatas hoje se veem o tempo todo instados a provar, para a sociedade, que o reconhecimento da doutrina como atividade médica é legítimo. Examinaremos a seguir algumas das principais estratégias de legitimação usadas para resguardar a doutrina de críticas, e, assim, evitar que se perca o reconhecimento obtido em 1980.

\section{Materiais e enfoque analítico}

A discussão a seguir se apoia em pesquisa documental realizada junto às principais revistas de homeopatia em circulação no Brasil, no período de 2002 a 2015. São elas: Revista de Homeopatia; Cultura Homeopática; e International Journal of High Dilution Research ${ }^{2}$. No período indicado, foram publicados 278 artigos completos

2. Os próprios homeopatas, em geral, reconhecem que essas são as principais publicações de homeopatia no país, como pude confirmar nas entrevistas que realizei como parte da pesquisa, com membros da diretoria das principais associações brasileiras de médicos e farmacêuticos homeopatas (a AMHB e a $\mathrm{ABFH})$. Decidi por esse recorte temporal porque cobre o período que vai da criação da revista Cultura Homeopática até o ano em que o International Journal of High Dilution Research - revista que sucede a Cultura Homeopática, como veremos - deixa de ter um brasileiro como editor-chefe. 
nessas revistas; esses artigos foram lidos, classificados e fichados de maneira sistemática como parte da pesquisa. Exponho em detalhe a metodologia e os resultados do levantamento em outro trabalho (Bárbara, 2018, pp. 645-713).

Tal pesquisa documental permitiu caracterizar não só as estratégias de legitimação adotadas por homeopatas, como também as controvérsias internas que os dividem. Como argumento a seguir, essas estratégias e controvérsias estão intersticialmente ligadas umas às outras.

Os proponentes da doutrina concebem as intermináveis controvérsias estabelecidas dentro dos círculos de homeopatas como um dos maiores obstáculos para sua propagação e consolidação. A ideia subjacente é que, se os homeopatas parassem, por um momento, de lutar entre si e se unissem para promover a doutrina, ela iria muito mais longe do que foi até aqui.

Mas o conflito, ao mesmo tempo que divide, vincula; ou, para ser mais exato: a divisão que se configura numa situação de conflito é também uma forma de socialização, que enlaça, de maneira específica, diferentes indivíduos e grupos ${ }^{3}$. Assim, a imaginação sociológica permite intuir que as controvérsias que se instituem no interior dos círculos de homeopatas, para além de limitarem o alcance da doutrina, estão relacionadas de maneira mais positiva à sua conservação - de modo que, no momento em que os homeopatas parassem de lutar entre si, algo indispensável à sobrevivência da doutrina teria se perdido. É essa intuição que desenrolo a seguir.

Há, para ser mais exato, muitas controvérsias que dividem os homeopatas. A seguir, veremos só uma delas: a controvérsia entre a corrente culturalista e a cientificista - que refletem as principais estratégias recentes de legitimação pública da doutrina no país.

\section{Dissidência e unidade nos círculos de homeopatas}

\section{Visão geral da controvérsia}

Ao folhear as revistas de homeopatia, encontramos registros só de uma parte da vida intelectual da doutrina: aquela cultivada por profissionais que trabalham com homeopatia e têm alguma inserção no sistema universitário brasileiro. Não está bem representada nessas revistas a perspectiva do paciente da homeopatia; nem as ideias

3. Uso o termo "socialização" no sentido visado por Simmel, isto é, como processo que resulta na emergência de entidades sociais. Simmel dedica um capítulo de sua Soziologie, de 1908, para discutir o conflito como forma de socialização (Simmel, 1992, pp. 284-382). Minha análise a seguir é inspirada pela sociologia simmeliana do conflito. 
de profissionais que trabalham com a doutrina, mas não contribuem para tais veículos, quer por já estarem satisfeitos em praticá-la no consultório, quer por serem praticantes leigos, sem filiação acadêmica.

Em todo caso, há uma razão para analisar em separado a contribuição intelectual dos profissionais que registraram suas ideias nas revistas de homeopatia: eles estão em posição vantajosa para promover a doutrina na esfera pública. Vários deles têm condições de influenciar a opinião pública e o poder público, justamente por sua inserção acadêmica. O ensejo para tal foi a Resolução 1000 do CFM: se a homeopatia é classificada como especialidade médica, é de se esperar que homeopatas consigam trabalhar onde também trabalham outros profissionais da mesma categoria - as universidades. Assim, as estratégias de legitimação que examinaremos têm um público específico: o acadêmico. Quando buscam convencer o cliente, ou o gestor público, do valor da doutrina, os homeopatas muitas vezes recorrem a outras estratégias de legitimação, adaptadas a tais públicos. Estas não são o tema principal deste artigo, e por isso só serão discutidas aqui marginalmente.

Em minha pesquisa documental, identifiquei duas correntes doutrinárias diferentes, que promovem, cada qual, uma estratégia específica de legitimação da homeopatia diante do público acadêmico. Chamo uma delas de corrente culturalista; ela é caracterizada, do ponto de vista doutrinário, pela instrumentalização dos referenciais teóricos das ciências humanas, e do ponto de vista sociológico, pela busca de alianças com intelectuais que dominam tais referenciais. A outra, que chamo de corrente cientificista, distingue-se da anterior pelo esforço de provar a validade da doutrina com base nos critérios das ciências naturais, e por alianças com pesquisadores dessas áreas.

Há uma revista que, em sua breve história, concentrou as duas tendências, uma em sucessão à outra. Ela nasce em 2002, sob o nome Cultura Homeopática - iniciativa de um pequeno círculo de médicos homeopatas da Escola Paulista de Homeopatia (EPH), como então era chamada. A EPH estava localizada na Vila Clementino, nos arredores da Associação Paulista de Homeopatia (APH) e de outras instituições médicas. Estava: hoje, não existe mais, e a Cultura Homeopática passou a se chamar International Journal of High Dilution Research (IJHDR), revista ligada a um grupo internacional de pesquisa.

A mudança de nome simboliza uma guinada em sua linha editorial e substrato social. A Cultura Homeopática nasce como uma revista de divulgação da EPH. Seus primeiros números têm menos de vinte páginas, recheadas de anúncios - a maioria de farmácias homeopáticas, que bancavam o periódico. Seu primeiro editor-chefe é um médico homeopata, um praticante da doutrina dotado de prestígio nos círculos de homeopatas, e além disso um erudito, versado em vários autores com os quais os intelectuais das ciências humanas estão familiarizados. 
A revista passa a ter ISSN e Conselho Editorial desde a quinta edição, publicada como volume especial, com mais de cem páginas e nove artigos originais. A partir daí, os anúncios perdem espaço; ela começa a publicar artigos em inglês; integra um número crescente de homeopatas estrangeiros em sua Comissão Editorial - enfim, apresenta-se cada vez mais como periódico científico, em vez de revista de divulgação.

A partir do número 16, a Cultura Homeopática passa a publicar, com regularidade, resumos de trabalhos apresentados nos simpósios do Groupe International de Recherche sur l'Infinitésimal (Giri). Trata-se aí de um grupo de pesquisa fundado em 1985 por dois pesquisadores franceses interessados em homeopatia, e cujo comitê executivo conta com seis membros; em 2017, três eram brasileiros. A parceria com o Giri anuncia a mudança na linha editorial que se consolidaria no número 22, com a alteração do nome.

Com a mudança, a revista deixa de ter como editor-chefe um médico homeopata, alinhado à corrente culturalista. Em seu lugar, entra um físico que pesquisa homeopatia em laboratório, sem praticá-la - alinhado à corrente cientificista. A revista então deixa de ser iniciativa de uma escola que ensina a homeopatia "na prática" para se tornar iniciativa de um grupo multidisciplinar de pesquisa - ficando sob controle de um círculo diferente de homeopatas. A partir daí, a IJHDR é indexada em várias bases de periódicos, e passa a receber um volume cada vez maior de contribuições internacionais, sobretudo da Índia - outro país onde a doutrina obteve considerável reconhecimento institucional.

Passemos agora à caracterização de cada corrente.

\section{A corrente culturalista}

Programa: a tese da racionalidade homeopática

Comecemos examinando como um homeopata alinhado à corrente culturalista imagina a situação atual da doutrina:

\footnotetext{
É mais do que evidente que temos duas grandes ações homeopáticas em curso: uma que baseia sua interlocução com o hardcore do pragmatismo biomédico, através de concessões epistemológicas exageradas, e a outra, que se move com lentidão, dispensa diálogos, e referencia sua posição no mundo como irretocável (Rosenbaum, 2002, p. 5).
}

A passagem consta do editorial da primeira edição da Cultura Homeopática. O editor da revista delineia aí duas posições distintas da sua. Em sua visão, nenhuma dessas duas posições levaria a homeopatia adiante. A primeira posição criticada 
corresponde à corrente cientificista; a segunda, a homeopatas ortodoxos, que, contentes com sua atuação clínica e com a palavra de Hahnemann, não se engajariam na reprodução da vida intelectual da doutrina. A posição culturalista, defendida pelo editor, é imaginada como uma terceira via, que evitaria o empedernimento da ortodoxia, sem precisar fazer as "concessões epistemológicas exageradas" feitas pelos cientificistas.

Essa é uma imagem negativa da corrente culturalista, que capta o que ela não almeja ser e as posições com as quais concorre nos círculos de homeopatas. Mas o que ela é em termos positivos?

Para termos uma ideia disso, vejamos como o mesmo autor reapresenta sua posição em um momento crítico da história recente da homeopatia: a publicação de uma metanálise no prestigioso periódico médico The Lancet, em 2005 (Shang et al., 2005). A metanálise, com resultado desfavorável para a homeopatia, saiu no The Lancet junto a um editorial, cujo título já diz tudo: "The end of homoeopathy". O augúrio do fim da homeopatia - que repercutiu em veículos da imprensa ao redor do globo - foi interpretado pelos homeopatas como ameaça, exigindo, destes, intensa mobilização para rebatê-lo, ou seja, para provar ao público o valor da doutrina em face de críticas contundentes da comunidade científica internacional.

Nas páginas da Cultura Homeopática, vemos que a resposta culturalista à ameaça envolve a intensificação da polêmica interna, em especial com a corrente cientificista. Se, no primeiro volume da revista, a posição cientificista é criticada em chave comedida - por seus exageros -, em texto escrito em resposta ao The Lancet, ela é caracterizada pelo mesmo autor como um "enfoque risível" e castigada por sua insistência em "afirmar uma precisão não possuída" (Rosenbaum, 2005, p. 4). A busca por legitimação da doutrina nos termos das ciências naturais estaria fadada ao fracasso. Em vez disso, a homeopatia devia buscar "outro tipo de precisão, outro tipo de resolutividade, um outro gênero de efetividade" (Idem). Que tipo? Vejamos:

A professora titular do Instituto de Medicina Social da Uerj, Madel Luz, vem colocando há muito que um modelo de pesquisa baseada no sujeito, nos moldes propostos pelas ciências humanas [...], ainda estava por ser montado pelos homeopatas. Destarte, a solução já está em processo de maturação: ao usar procedimentos interpretativo-compreensivos, típicos das ciências humanas, tendo a linguagem como referência fundamental de avaliação, poder-se-á ajudar a validar o saber médico da homeopatia sem usar a referência nosográfica como norte absoluto de seu sucesso terapêutico. (Idem).

O cerne do argumento de Madel Luz, a quem o autor aí se refere, é que os critérios usados para avaliar a eficácia dos recursos terapêuticos convencionais não 
se aplicariam à homeopatia. Essa prática se basearia em uma "racionalidade" não só diferente, mas incomparável com a da medicina convencional (Luz, 1988, pp. 141-5; Luz, 2003, p. 6). Por isso, afirmações como "os preparados homeopáticos não são eficazes" só fariam sentido se complementadas por algo como: "com base na racionalidade médica convencional”. Para Luz, a escolha pela racionalidade homeopática ou pela "biomédica" seria, em última análise, uma questão de fé (Luz, 1996, p. 164) $)^{4}$.

Vou me referir a essa ideia como a tese da racionalidade homeopática. Essa tese não é defendida só em revistas de homeopatia. A expressão "racionalidade homeopática" consta, por exemplo, do relatório do Projeto Nacional de Práticas Integrativas e Complementares, que promove a oferta dessas práticas no sus (Ministério da Saúde, 2015, p. 45). E variantes dessa tese aparecem em outros trabalhos de sociologia da saúde e história da medicina, ainda que, em alguns casos, o argumento seja formulado não com base na ideia de "racionalidade", mas com base em conceitos como o "paradigma" (tirado de Kuhn), “episteme” (de Foucault) e "universos simbólicos" (de Berger \& Luckmann $)^{5}$. Se temos, nesses casos, usos exegeticamente corretos desses conceitos é uma questão que deixo em aberto neste artigo; o que interessa é observar que, na prática, há homeopatas que usam esses conceitos como instrumentos de salvação da doutrina. Ou seja: como recursos intelectuais por meio dos quais visam, a um só tempo, (a) a defender a doutrina das críticas da comunidade científica, e (b) a promover uma via específica de salvação dentre as ofertadas nos círculos de homeopatas, de maneira a disputar prestígio no interior desses círculos. $\mathrm{O}$ apelo especial da tese de Luz para os homeopatas é claro: caso seja verdadeiro que a doutrina opera com base em uma "racionalidade" própria, críticas da comunidade científica, como as do The Lancet, seriam inócuas, e formuladores de políticas públicas teriam motivo para ignorá-las. E os homeopatas da linha culturalista usam a tese para tentar convencer não homeopatas da legitimidade da doutrina.

Homeopatas bem-sucedidos em convencer tal público externo ganham prestígio dentro de sua própria comunidade - e, a não ser que uma liderança intelectual consiga se impor sobre as demais (o que não é o caso nos círculos de homeopatas no Brasil), é de se esperar que a aquisição de prestígio por esse meio leve ao acirramento do conflito interno. Dois fatores são decisivos para esse resultado:

4. Faço a crítica detalhada desse argumento e de suas variantes - que considero falhos em inúmeros pontos - em Bárbara, 2018, pp. 193-200; 326-332. Não é, porém, objetivo deste artigo discutir o mérito do argumento, pois o enfoque é sua instrumentalização por parte dos homeopatas.

5. O editor da Cultura Homeopática, por exemplo, emprega o termo "episteme" no editorial acima citado. Para dois exemplos de trabalhos publicados no âmbito das humanidades, cf. Monteiro \& Iriart, 2007; e Fiore, 2015. 
(1) O imperativo de explorar novos horizontes conceituais para legitimar a doutrina diante do público externo, determinado pela ameaça do fim da homeopatia, exige engajar o maior número possível de adeptos dentro dos círculos de homeopatas, mas tal exigência encontra oposição nas facções doutrinárias já estabelecidas, ou que buscam se estabelecer por meio da exploração de outros horizontes conceituais. No caso, vemos que a promoção da estratégia culturalista envolve a negação da estratégia cientificista, além da crítica à ortodoxia - o que, é claro, gera atrito entre os homeopatas que apostam suas fichas nessas outras estratégias. O que está aí em jogo é a disputa interna aos círculos de homeopatas pela definição de qual homeopatia é a "verdadeira" homeopatia.

(2) A exploração de certo repertório conceitual a princípio alheio à doutrina - como conceitos desenvolvidos por sociólogos e historiadores, com os quais homeopatas da linha culturalista acreditam ser possível salvá-la - exige um grau considerável de empenho intelectual. O mesmo vale para homeopatas que optam pela outra via, a cientificista: a familiarização com a forma e o conteúdo próprios de uma ou de outra tradição intelectual requer tempo e dedicação. O corolário disso é que a familiarização com qualquer uma dessas duas tradições dificulta o domínio da outra. Embora haja um ou outro homeopata que se esforce em unir as duas correntes - em unir as correntes culturalista e cientificista -, na maioria dos casos tal dificuldade se resolve por meio da familiarização com apenas uma dessas tradições intelectuais.

E esse segundo ponto tem um desdobramento importante: uma vez familiarizado com esse ou aquele repertório conceitual, este se torna, ao menos para esse subconjunto de homeopatas, algo além de um escudo retórico usado só em ocasiões excepcionais - influenciando a forma como a doutrina é imaginada e comunicada pelos adeptos de uma ou outra corrente, e mesmo praticada na clínica. É o que veremos a seguir.

Desdobramentos formais do programa culturalista

A tese da racionalidade homeopática é só um exemplo de uma tendência estilística geral, própria da corrente culturalista. Os artigos publicados nas revistas de homeopatia por autores alinhados a tal corrente amiúde trazem trechos que parecem extraídos de uma tese defendida em algum departamento de ciências humanas, se considerados só quanto à sua temática e ao padrão estilístico ${ }^{6}$.

6. Isto é, sem levar em conta a qualidade desses trabalhos. Diga-se que, com poucas exceções, o uso dos referenciais das ciências humanas que encontramos nas revistas de homeopatia é pouco criterioso. 
Assim, homeopatas alinhados à corrente culturalista escrevem sobre processos de atribuição de sentido (Moraes, 2005, pp. 6-7), dialética (Triana, 2004, p. 29), subjetividade e cuidado de si (Rosenbaum \& Priven, 2006, p. 8), o caráter histórico do conhecimento (Solon, 2002, p. 47), a relação de forma e conteúdo na arte (Stiefelmann, 2011, p. 46) etc. - o tipo de assunto que se esperaria encontrar em publicações de filosofia, história, sociologia, teoria da comunicação ou antropologia, mas não em artigos escritos por médicos homeopatas e publicados em uma revista voltada a profissionais da medicina. Reproduzo aqui uma dessas citações, só para ilustrar o ponto:

Adota-se aqui o modelo interacionista ou ativista do conhecimento [...]: o médico homeopata é o sujeito do conhecimento; o doente, o objeto do conhecimento; a homeopatia, o produto do conhecimento. [...] O doente é, dialeticamente, o sujeito histórico de sua doença e, ao mesmo tempo, o objeto de conhecimento do médico homeopata. O médico homeopata é o sujeito de conhecimento de outro sujeito: o doente, contudo o homeopata é igualmente, sujeito de seu próprio sofrimento. Na instabilidade dessas circunstâncias, a verdade será sempre relativa, misteriosamente arquivada nos processos naturais e sociais (Solon, 2002, p. 47).

Em linha com isso, encontramos, ao folhear as páginas das revistas de homeopatia, referências a vários autores canônicos nas humanidades, como: Adorno \& Horkheimer, Aristóteles, Bachelard, Barthes, Berger \& Luckmann, Canguilhem, Cassirer, Durkheim, Eco, Foucault, Gadamer, Ginzburg, Goffman, Habermas, Hegel, Heráclito, Husserl, Kant, Kierkegaard, Kuhn, Lévi-Strauss, Marx, Merleau-Ponty, Peirce, Ricœur, Saussure, Vygotsky, Warburg e Weber.

Em termos de estilo, vemos que os homeopatas alinhados à corrente culturalista dão grande valor às demonstrações de erudição - mostras de que leram autores de ótima reputação intelectual e de que dominam suas ideias, a ponto de conseguirem relacioná-las com as do criador da homeopatia. Isso não só aproxima tais trabalhos do que às vezes fazemos nas humanidades, como ainda os afasta dos textos da corrente cientificista, cujo modelo são os artigos científicos publicados nos periódicos das ciências naturais, que em geral não abrem espaço para demonstrações de erudição e têm estilo puramente técnico.

Como parte do levantamento que conduzi, classifiquei o teor dos artigos publicados no período de referência, nas três revistas investigadas. A Tabela 1 resume tais achados. Ela mostra que a Cultura Homeopática e a Revista de Homeopatia - outra revista cujo editor-chefe é um médico homeopata - concentram mais exposições temáticas do que o IJHDR. Trata-se aí de textos dissertativos e argumentativos, mais compatíveis com demonstrações de erudição e exercícios exegéticos. Essas revistas, 
e em especial a Revista de Homeopatia, também abrem mais espaço para relatos de experiência clínica - e várias das referências aos autores que mencionei são mobilizadas como parte desses relatos, conforme veremos a seguir.

TABELA 1

Artigos por teor e revista publicada

\begin{tabular}{|c|c|c|c|c|c|c|}
\hline RUBRICA GERAL & TEOR DO ARTIGO OU PESQUISA & $\begin{array}{l}\text { TOTAL DE } \\
\text { ARTIGOS }\end{array}$ & $\mathrm{CH}(\%)$ & $\operatorname{IJHDR}(\%)$ & $\mathrm{RH}(\%)$ & TOTAL (\%) \\
\hline \multirow{5}{*}{$\begin{array}{l}\text { Teoria homeopáti- } \\
\text { ca: diálogos com a } \\
\text { literatura }\end{array}$} & Revisão bibliográfica (metodologia) & 12 & $7 \%$ & $5 \%$ & $1 \%$ & $4,3 \%$ \\
\hline & Revisão bibliográfica (outros) & 33 & $16 \%$ & $8 \%$ & $12 \%$ & $11,9 \%$ \\
\hline & Revisão bibliográfica (sistemática) & 5 & $1 \%$ & $3 \%$ & $1 \%$ & $1,8 \%$ \\
\hline & Exposição de projeto & 18 & $6 \%$ & $6 \%$ & $8 \%$ & $6,5 \%$ \\
\hline & Exposição temática ou conceitual & 48 & $22 \%$ & $8 \%$ & $23 \%$ & $17,3 \%$ \\
\hline \multirow{3}{*}{$\begin{array}{l}\text { Relatos e ensaios } \\
\text { de conduta clínica }\end{array}$} & Relato clínico (um caso) & 23 & $8 \%$ & $2 \%$ & $16 \%$ & $8,3 \%$ \\
\hline & Relato clínico (vários casos) & 20 & $8 \%$ & $4 \%$ & $10 \%$ & $7,2 \%$ \\
\hline & Estudo clínico & 10 & $0 \%$ & $5 \%$ & $6 \%$ & $3,6 \%$ \\
\hline \multirow{6}{*}{$\begin{array}{l}\text { Técnica homeopá- } \\
\text { tica aplicada fora } \\
\text { da clínica }\end{array}$} & Pesquisa patogenética & 12 & $3 \%$ & $2 \%$ & $8 \%$ & $4,3 \%$ \\
\hline & Experimento botânico & 13 & $1 \%$ & $10 \%$ & $2 \%$ & $4,7 \%$ \\
\hline & Experimento farmacotécnico & 4 & $3 \%$ & $0 \%$ & $1 \%$ & $1,4 \%$ \\
\hline & Experimento in vitro & 13 & $1 \%$ & $10 \%$ & $2 \%$ & $4,7 \%$ \\
\hline & Análise físico-química & 4 & $0 \%$ & $4 \%$ & $0 \%$ & $1,4 \%$ \\
\hline & Teste com animais & 32 & $10 \%$ & $23 \%$ & $0 \%$ & $11,5 \%$ \\
\hline \multirow{3}{*}{$\begin{array}{l}\text { Pesquisa em aspec- } \\
\text { tos não clínicos e } \\
\text { não técnicos }\end{array}$} & Análise demográfica & 4 & $2 \%$ & $0 \%$ & $2 \%$ & $1,4 \%$ \\
\hline & Pesquisa de percepção & 17 & $8 \%$ & $5 \%$ & $6 \%$ & $6,1 \%$ \\
\hline & Pesquisa historiográfica & 10 & $3 \%$ & $5 \%$ & $2 \%$ & $3,6 \%$ \\
\hline
\end{tabular}

Desdobramentos práticos do programa culturalista

Vimos como o programa culturalista impacta a forma como alguns homeopatas se comunicam entre si; nesta seção, examinaremos como isso se articula na prática, 
ou seja, seus desdobramentos clínicos. Apresento aqui dois deles ${ }^{7}$ a a prescrição de homeopatia visando a tratar "patologias sociais"; e o apoio em ideias da semiótica para ampliar o escopo do diagnóstico homeopático.

Ao folhearmos as revistas de homeopatia, aprendemos que vários homeopatas atribuem poderes extraordinários à doutrina: acreditam que, se o homeopata indicar o símile certo ao paciente, será capaz de curar não só sua saúde física e mental, como também remediar sua vida como um todo. Esse "todo" inclui, para alguns homeopatas, a dimensão social da vida. Esse é o mundo dos homeopatas que prescrevem beladona, mercúrio, veneno de surucucu e de tarântula, carbonato de cálcio, nux vomica, fósforo, enxofre, potássio etc. - sempre preparados homeopaticamente -, sob a promessa de que teriam o poder de tratar "patologias sociais” como a predisposição ao crime (Barollo et al., 2007); o abandono da família (Ikegami, 2005); e o comprometimento das capacidades de interação de crianças neuroatípicas (Solon, 2004) ${ }^{8}$.

Hahnemann, o criador da homeopatia, já concebia a doutrina como uma medicina que ia além do plano fisiológico; mas a analogia com a patologia social lhe era estranha. Tal novidade é própria dos homeopatas da corrente culturalista. Eles partem da ideia de que "tornar as pessoas saudáveis" exige um esforço concomitante de tratar as "patologias sociais" que impactam a saúde física e mental dessas pessoas - ideia que, se reproduzida de maneira isolada e em chave genérica, faz todo sentido. Sabemos bem, desde Durkheim, com seu trabalho sobre o suicídio (ou desde Engels, com sua obra sobre as condições da classe trabalhadora da Inglaterra), que certas "patologias sociais" impactam a saúde individual.

A questão é que, cultivada no solo da homeopatia, a ideia dá frutos que Durkheim e Engels não imaginariam - como é o caso da aposta de que o símile homeopático seria um bom remédio para tais males. Na prática, isso significa prescrever, para uma criança com diagnóstico de hiperatividade que mora na periferia de uma cidade grande, veneno de tarântula agitado e diluído duzentas vezes na proporção de 1 para 100, em parte porque tal criança já teve pesadelos "de perseguição por fantasmas, pela morte, pelo lobisomem" - sintoma considerado, segundo os cânones da homeopatia, similar ao provocado pelo veneno de tarântula em pessoas saudáveis (Barollo et al., 2007, pp. 8-9)9.

7. Identifiquei, em minha pesquisa, outros desdobramentos. Limito-me a dois por questão de espaço.

8. As substâncias do arsenal homeopático que mencionei foram tiradas dos artigos citados, e usadas com tal propósito.

9. Para a sorte do paciente pediátrico que recebeu a prescrição, depois de diluído duzentas vezes na proporção de 1 para 100, não resta mais nenhum traço de veneno de tarântula nos glóbulos que ele ingere. Na prática, para o paciente, todos os preparados homeopáticos são iguais - a não ser que erros no processo de confecção acarretem em contaminação, como já aconteceu. Apesar disso, para o homeopata, prescrever o símile certo é muito importante: ele acredita que o tratamento só funciona caso o símile 
O segundo exemplo está relacionado com o uso da semiótica para fins de diagnóstico. Esse é o mundo dos homeopatas que, para chegarem ao símile considerado certo, levam em conta desenhos de seus pacientes (Stiefelmann, 2011), ou sua indumentária e ornamentos (Priven \& Jurj, 2009).

Para ilustrar o ponto, consideremos o segundo artigo. Seus autores partem de uma crítica a um aspecto do roteiro de diagnóstico homeopático, a saber: seu "logocentrismo". Trata-se aí da centralidade da anamnese para o diagnóstico homeopático. Para chegar ao símile correto, os homeopatas comparam os sintomas do paciente com textos canônicos da homeopatia (e em especial, com os textos escritos por Hahnemann há dois séculos); e a maior parte dos homeopatas dá ênfase especial ao sintoma tal como verbalizado pelo paciente na anamnese (para uma discussão pormenorizada desse roteiro de diagnóstico, cf. Bárbara, 2018, pp. 399-454). Os autores do artigo em questão concebem isso como uma limitação, e se apoiam em ideias tiradas da semiótica para propor algo novo: que o homeopata aprenda a interpretar signos não verbais de comunicação - por meio dos quais o paciente "diz" algo sobre seu estado, sem usar palavras - e se valha disso na seleção do símile homeopático.

Para ilustrar como a ideia pode ser posta em prática, os autores convidam seus colegas homeopatas a responderem a questão: "O que as mãos, por exemplo, podem revelar?” - e então apresentam a fotografia de um par de mãos. São mãos femininas, e têm aspecto inchado; estão ornadas com anéis dourados (uns com brilhantes, outros sem) em quase todos os dedos, e com uma pulseira também dourada; as unhas estão pintadas com esmalte brilhante, em tom de azul (Priven \& Jurj, 2009, p. 13). Eis então como os autores respondem à questão antes formulada:

Do ponto de vista mental: extravagância; desejo de usar joias; excentricidade; a paciente esbanja dinheiro e é ostentosa. A coerência mútua destes signos pode ser demonstrada através de uma análise repertorial (Idem).

A "análise repertorial" é o passo do roteiro de diagnóstico homeopático no qual se traduzem os sintomas obtidos na consulta para o jargão próprio dos homeopatas, a linguagem repertorial, para com isso determinar qual seria o símile correto para essa paciente. Nesse caso, a análise repertorial - que inclui, mas não se limita aos dois sintomas mencionados na citação: "extravagância" e "excentricidade" - mostra que o símile correto seria a beladona. $\mathrm{E}$ o que os autores defendem é que as lições

escolhido esteja certo. Sabemos disso não só pelo testemunho de muitos homeopatas, como também por meios mais indiretos. Por exemplo: as provas exigidas para a obtenção do título de especialista em homeopatia cobram do médico aspirante a homeopata que prove sua proficiência em escolher o símile certo, conforme o cânone da doutrina (Bárbara, 2018, pp. 406 et seq.). 
da semiótica ajudam o homeopata a chegar à prescrição adequada à individualidade do paciente.

O que temos, nos dois casos que apresentei, são diferentes exercícios de costura entre ideias cultivadas no âmbito das humanidades e ideias cultivadas só nos círculos de homeopatas. Deve ficar claro que se, de um lado, os casos que apresentei não representam a regra do atendimento homeopático, de outro não são casos isolados. Dentre os artigos citados, temos alguns assinados por homeopatas com bastante prestígio em seu meio. Mas o mais decisivo é que, embora seja pequeno o número de homeopatas que aderem a esta ou àquela inflexão particular do culturalismo - como tratar "predisposição ao crime” com homeopatia, ou levar em conta signos não verbais de comunicação para fins de prescrição -, há uma linha que conecta essas "particularidades" em uma só corrente: o programa culturalista. Tais "particularidades" são a consequência previsível da estratégia de buscar alianças com intelectuais das humanidades e explorar tal repertório conceitual à procura de meios para blindar a doutrina das críticas da comunidade científica. O contato e a familiarização com as ideias gestadas nos círculos acadêmicos das humanidades fazem com que seja só uma questão de tempo até que algum homeopata tome a iniciativa de usá-las em outros contextos de atuação - como na interação com os pacientes, mas também na disputa, travada com outros homeopatas, pela definição de qual é a "verdadeira homeopatia”.

Por isso, devemos agora retomar a controvérsia com a corrente cientificista. Até o momento, examinamos esta sobretudo da perspectiva que se opõe a ela: vimos como é imaginada pelos homeopatas de persuasão culturalista. Vejamos, agora, como os autores alinhados a tal corrente a imaginam.

\section{A corrente cientificista}

Programa: a produção de evidências científicas da homeopatia

Comecemos pelo elemento que o cientificismo tem em comum com o culturalismo: a crítica à ortodoxia. Vejamos como ela é formulada pelo farmacêutico que assume, na condição provisória de editor convidado, a Cultura Homeopática:

\footnotetext{
[...] enquanto o método experimental de Bernard foi se atualizando com o enorme progresso das ciências, os homeopatas - entendendo que sua prática continha princípios imutáveis não se preocuparam com as questões em jogo no domínio das ciências (Fontes, 2007, p. 8).
} 
O médico e o farmacêutico, portanto, concordam nisto: a homeopatia precisa mudar, atualizar-se. A diferença emerge quando perguntamos: mas mudar como? Em que direção? Nas palavras do mesmo editor:

A ciência clássica vem cedendo espaços cada vez mais significativos à nova racionalidade científica [...]. Nessa perspectiva, sem abrir mão de seus principais fundamentos, cabe à homeopatia dedicar-se cada vez mais à produção do conhecimento científico, à revisão de suas terminologias, à atualização de seus conceitos e à extinção de feudos do conhecimento homeopático, a fim de ser aceita no mundo acadêmico. Com isso, as agências de fomento e as Instituições de Ensino Superior poderão abrir mais francamente espaços formais para o ensino e o desenvolvimento da produção científica na área da homeopatia (Fontes, 2007, p. 8).

Aqui também temos menção à “racionalidade científica”. Mas, embora a palavra seja a mesma usada por Luz, o sentido é outro, em um aspecto importante. Aqui desponta a ideia de que há duas racionalidades cientificas: uma antiga, positivista, que seria, esta sim, incompatível com a homeopatia; e outra nova, compatível com a homeopatia. Essa nuance no uso do termo tem a função de "autorizar" o homeopata a explorar o horizonte conceitual das ciências naturais, e a fazer experimentos nos moldes dos publicados em periódicos de medicina, biologia, física e química - o que homeopatas alinhados à corrente culturalista consideram um beco sem saída, como vimos.

Para pôr em perspectiva o programa cientificista, cabe mencionar que muitos homeopatas apresentam a doutrina para o público como uma "medicina do sujeito", que valoriza acima de tudo a relação médico-paciente. $\mathrm{O}$ seguinte bordão captura bem a ideia: "a homeopatia trata o doente, e não a doença". Nesse ponto, ela seria distinta da medicina convencional. Com efeito, a consulta com o homeopata é, muitas vezes, mais demorada e atenciosa do que a convencional; e muitos pacientes que se tratam com homeopatia valorizam a escuta atenciosa que lhes é dispensada na interação com o médico ${ }^{10}$. Esse é um traço importante do apelo da doutrina para os pacientes, em particular dos insatisfeitos com o atendimento convencional. Mas também há um bom grau de idealização nesse bordão. De um lado, esse não é um traço distintivo da homeopatia, pois também há médicos convencionais que valorizam a relação com o paciente. De outro lado, tal idealização falha em capturar uma parte muito importante da atividade dos profissionais que trabalham com homeopatia - como a do farmacêutico que confecciona os preparados homeopáticos prescritos pelo médico. Ao contrário da escuta atenciosa, a farmacotécnica

10. Para um levantamento qualitativo cuidadoso de algumas das representações de pacientes, cf. Monteiro \& Iriart, 2007; sobre a valorização da escuta atenciosa, ver em especial as pp. 1909-1910. 
homeopática é um traço distintivo da doutrina, isto é: uma atividade desempenhada só por quem se identifica com a homeopatia.

Ao folhear as páginas do IJHDR, temos uma ideia bastante concreta dessa parte da homeopatia que não cabe na ideia da "medicina do sujeito" - parte essa que é representada e acolhida pela corrente cientificista.

Como mencionei, a metamorfose da Cultura Homeopática no International Journal of High Dilution Research envolve uma mudança na linha editorial e no substrato social da revista. Quem assume o posto de editor-chefe, pouco antes da mudança de nome, não é um médico homeopata, e sim, primeiro, um farmacêutico, e, em seguida, o que chamo de pesquisador puro de homeopatia - no caso um físico que pesquisa, em laboratório, as propriedades das "ultradiluições" (bigh dilutions, em inglês). Trata-se aí, portanto, de profissionais que trabalham em diferentes círculos da comunidade homeopática.

Uma "ultradiluição" é uma substância submetida à farmacotécnica concebida por Hahnemann - com a diferença de que já não importa se ela é ou não, depois de ser assim produzida, prescrita segundo a lei dos semelhantes. Com a mudança de nome, fica claro que o enfoque principal da revista deixa de ser as atividades realizadas no consultório, em contato com o paciente, e passa a ser as desenvolvidas longe dele, no laboratório onde os glóbulos homeopáticos são confeccionados. Nas palavras do editor-chefe que assume a revista:

\footnotetext{
Existem diferenças entre a arte e a ciência de curar. A arte é exercida amplamente nos consultórios, clínicas e hospitais. Mas o exercício da ciência exige outros tipos de raciocínios, vícios e metodologias, para os quais um homeopata tradicional não é treinado. Com isso, existe uma parte da comunidade científica aberta a pesquisar o fenômeno homeopático, porém, carente de informações sobre o mesmo (Zacharias, 2007, p. 4).
}

Vemos aí com clareza que o ponto de partida do programa cientificista é a separação entre a "arte" e a "ciência" homeopáticas, de modo que a proposta da revista é dedicar-se a esta última. Isso implica abordar a doutrina de uma perspectiva multidisciplinar - que inclui as ciências sociais, mas põe no primeiro plano a farmacologia, a física, a química e a biologia. E é sobretudo a esse público que os homeopatas da corrente cientificista voltam seus esforços de persuasão: para eles, a via de salvação da doutrina está na produção de evidências científicas "duras" de que a homeopatia funciona.

Isso basta para caracterizar o programa cientificista. Vamos agora à sua articulação. 
Nos artigos alinhados à corrente cientificista, o que vemos com mais frequência são relatos de experimentos, cujo modelo são artigos publicados em periódicos científicos das "ciências duras".

A Tabela 1 permite identificar isso rapidamente. Mais da metade (53 de 100) dos artigos publicados no IJHDR reportam experimentos. Na Cultura Homeopática, esses são 17 dos 88 artigos publicados no período (pouco menos de 20\%), sendo que 3 deles saíram nos números 20 e 21 (fase de transição da revista, que já contava com novo editor, mas não havia mudado de nome). Na Revista de Homeopatia, a proporção é ainda menor: só 12 dos 90 artigos publicados no período (13\%) reportam resultados experimentais.

Trata-se aí também de artigos assinados por múltiplos autores: ao todo, 146 dos 278 artigos completos que fichei (quase 53\%) foram assinados por mais de um autor, e 113 (pouco mais de 41\% sobre o total), por três ou mais autores. Há uma forte concentração desses artigos no IJHDR: 71\% dos artigos ali publicados são assinados por mais de um autor, e $62 \%$, por três ou mais; o percentual cai para $38 \%$ e $24 \%$ na Revista de Homeopatia (ou 34 e 22 artigos, num total de 90), e 47\% e 33\% na Cultura Homeopática (ou 41 e 29 artigos, num total de 88). Em vários casos, trata-se de equipes multidisciplinares - outra tendência da produção científica contemporânea.

Além disso, no lugar do culto à erudição, temos o culto ao número: mais importante do que demonstrar a capacidade de estabelecer relações entre as ideias de intelectuais de reputação consolidada, é dialogar com a literatura científica mais atual e dar mostras de domínio de métodos de análise estatística e ferramentas de teste de hipóteses. Se, para um homeopata da linha culturalista, é crucial atentar ao que os filósofos, sociólogos, teóricos da comunicação etc. revelariam sobre o mundo à nossa volta - pois aí poderia estar a chave para salvar a doutrina -, para um homeopata de persuasão cientificista, é preciso ter o olhar atento para o que se passa no contexto controlado do laboratório: para o que valores-p, ratos Wistar e placas de Petri revelariam sobre esse mesmo mundo.

Boa parte desses trabalhos é de baixa qualidade metodológica ${ }^{11}$; uma das principais razões pelas quais tais artigos são publicados em revistas de homeopatia é porque tendem a ser rejeitados, se submetidos a outros periódicos. Apesar disso, tais trabalhos encontram acolhida no sistema universitário - os experimentos ali

11. Algo análogo ao que vemos nos textos da corrente culturalista: as referências a intelectuais canônicos das humanidades estão lá, mas em geral são manejadas de maneira questionável. Temos a forma, mas, via de regra, o conteúdo correspondente não é de qualidade. 
relatados são não raro conduzidos em programas de pós-graduação em áreas como farmacologia e veterinária.

\section{Desdobramentos práticos do programa cientificista}

Do ponto de vista da doutrina, a corrente cientificista tende a isolar um dos princípios que distinguem a homeopatia (sua farmacotécnica), e a desconsiderar o outro (a lei dos semelhantes). Isso abre espaço para o que chamo de homeopatia sem sujeito. A doutrina, hoje, não é praticada no Brasil só por médicos registrados no CFM, mas também por dentistas, veterinários, engenheiros agrônomos e praticantes leigos (nesse último caso, de maneira irregular). E é tal abertura que permite a identificação da atividade de veterinários (em especial, dos que aplicam homeopatia a animais de produção) e agrônomos como homeopática. Esse é o mundo dos homeopatas que usam homeopatia para fins de engorda de porcos (Coelho et al., 2014) e galinhas (Lemos et al., 2011), ou para aumentar a taxa de crescimento de mudas de alface (Rossi et al., 2006).

Grande parte dos experimentos veiculados nas revistas de homeopatia investigadas - concentrados, na sua maioria, no IJHDR - se encaixa na categoria: o que engloba desde experimentos como os mencionados acima, até ensaios pré-clínicos com camundongos (Alecu et al., 2007). Nesse último artigo, o objetivo é avaliar o potencial da arnica preparada homeopaticamente na recuperação de fraturas em camundongos. A escolha da arnica não se baseia no roteiro de diagnóstico da homeopatia, que exigiria reconstruir o conjunto dos sintomas de cada camundongo; antes, baseia-se em um sintoma isolado (a pata quebrada), que os próprios experimentadores produziram no animal. Já em Lemos et al., 2011, temos um exemplo - entre outros achados na pesquisa - de experimento in vitro. No primeiro caso, temos paciente (os camundongos), mas não um conjunto de sintomas, e o paciente não é tratado como se esperaria de uma "medicina do sujeito"; no segundo, não temos nem paciente, nem sintoma. Daí me referir a tais casos como "homeopatia sem sujeito".

O segundo caso, em particular, envolve a confecção do que os homeopatas chamam ora de "nosódio", ora de "bioterápico": um preparado homeopático que toma como base não uma planta ou um mineral (as bases mais comuns do arsenal homeopático), mas sim patógenos e excreções patológicas (por exemplo: pedaços de tumor extraído por biópsia, muco nasal de uma pessoa doente etc.). Em Lemos et al., 2011, temos um bioterápico preparado com o patógeno responsável pela microplasmose aviária - doença respiratória que os avicultores conhecem bem, já que pode prejudicar o crescimento das aves e, assim, afetar seus negócios. O experimento relatado não busca avaliar a eficácia do bioterápico, e sim sua segurança; mas o que 
confere sentido ao artigo é a proposta de usar o preparado como um tipo de "vacina", vendida para avicultores ${ }^{12}$.

A maior parte dos desdobramentos práticos da corrente cientificista, dos registrados nas páginas das revistas de homeopatia, se atém ou ao âmbito da pesquisa, ou ao âmbito do uso clínico em pacientes não humanos - o que está ligado à circunstância de que os principais representantes de tais correntes não são médicos homeopatas, e sim farmacêuticos ou profissionais das carreiras secundárias da homeopatia.

Mas várias dessas substâncias chegam ao mercado. Esse foi o caso do coroninum $30 \mathrm{CH}$, bioterápico à base de secreção e muco nasal de pessoas contaminadas com Covid-19, e que pode ser comprado em algumas farmácias homeopáticas. O coroninum $30 \mathrm{CH}$, embora não seja endossado pela Associação Médica Brasileira de Homeopatia (a mais importante associação de médicos homeopatas no país), é iniciativa de homeopatas, e em especial dos alinhados à corrente cientificista. Uma edição recente do IJHDR traz, inclusive, os resumos do encontro extraordinário do Giri em 2020, realizado em parceria com a UFRJ, e dedicado a discutir "as diferentes abordagens homeopáticas no tratamento de Covid-19, como o uso de nosódios (preparados a partir de partículas de vírus)" (Holandino \& Kokornaczyk, 2021, p. 1; tradução minha).

\section{Conclusão}

A controvérsia entre culturalismo e cientificismo divide os homeopatas. Nem todo homeopata defende o uso de bioterápicos ou acredita que as ultradiluições funcionam se utilizadas sem levar em conta a lei dos semelhantes, como propõem os cientificistas. Mas só os homeopatas creem que ela funciona: a crença não é compartilhada pela comunidade científica.

Por isso mesmo, quando médicos e farmacêuticos homeopatas querem provar o valor da doutrina diante da opinião pública, não há divergência doutrinária que os impeça de usar os instrumentos de salvação forjados por seus colegas cientificistas para tentar legitimar a doutrina diante do público acadêmico. O dossiê "Evidências

12. O que temos aqui é uma pseudovacina: pois as vacinas convencionais contêm algo como um princípio ativo - o patógeno atenuado, as proteínas de sua membrana celular, seu RNA etc. -, que são detectáveis por meio de análise microbiológica. O que não é o caso das "vacinas" homeopáticas: a diluição em série própria da farmacotécnica homeopática não deixa traço da substância original. Isso é ilustrado até mesmo pelo artigo que mencionei, em que os autores relatam que a análise das diluições homeopáticas que eles mesmo conduziram revelou não haver ali mais nenhum traço do patógeno (Lemos et al., 2011, pp. 365-366). Os autores, porém, não extraem daí um questionamento da doutrina, e sim a conclusão positiva de que, uma vez que o preparado não contém traços do patógeno, é seguro para ser usado em aves. 
Científicas da Homeopatia”, publicado em 2017 pela Revista de Homeopatia, com apoio da $\mathrm{AMHB}$, traz artigos de revisão de literatura sobre os efeitos dos preparados em plantas e in vitro. Na comunicação com o público amplo, a homeopatia sem sujeito é acolhida mesmo por homeopatas que, em outras ocasiões, repetem o bordão de que a homeopatia é a medicina do sujeito - que convenceu alguns sociólogos e gestores públicos a apostar nela, apesar de dois séculos de crítica bem fundamentada da comunidade científica.

Com isso em vista, reexaminemos a intuição central de que partimos: que o conflito interno aos círculos de homeopatas não é só um obstáculo à difusão da doutrina, mas está relacionado com sua conservação.

O que está aqui em jogo é a especialização de diferentes círculos de homeopatas na busca por legitimar, cada qual, um dos principais componentes doutrinários distintivos da homeopatia: seu roteiro de diagnóstico peculiar, que gira em torno da lei dos semelhantes; e sua farmacotécnica. Os atritos que emergem entre diferentes homeopatas - que eles enxergam como obstáculo à promoção da doutrina - podem, com isso, ser postos sob nova perspectiva: são um subproduto dessa especialização, que otimiza os esforços dos vários indivíduos implicados na reprodução da doutrina, na medida em que permite prospectar o maior número possível de linguagens conceituais com as quais se espera legitimá-la publicamente, além de forjar alianças em diferentes círculos sociais. As controvérsias que dividem os homeopatas são, em resumo, um efeito secundário da luta simbólica pelo reconhecimento da doutrina no circuito universitário brasileiro.

Tais controvérsias não são sinal da ruína da doutrina, e sim resultados da estratégia de diversificação simbólica que possibilita sua sobrevivência no contexto moderno feito raro, se considerarmos que tantos outros recursos terapêuticos que perderam legitimidade científica também perderam, junto com ela, legitimidade pública. Tal feito ainda sinaliza um ponto importante: que o negacionismo científico, que teve na onda da cloroquina uma de suas manifestações mais agudas na nossa história recente, tem raízes profundas. Temos uma longa tradição de negação da ciência, e ao menos parte dessa tradição se reproduz não em gabinetes políticos, mas lá onde seria de se esperar que a legitimação científica importasse mais: no nosso sistema acadêmico. 


\section{Referências bibliográficas}

Alecu, Adian et al. (2007), "Efeito do medicamento homeopático Arnica montana 7CH no traumatismo mecânico em camundongos”. Cultura Homeopática, 20 (3): 16-18.

BÁRBARA, Lenin. (2018), Investigações sobre a ignorância humana: uma introdução aos estudos da ignorância, acompanhada de um exame sociológico sobre a persistência da homeopatia e a consolidação do masculinismo ontem e hoje. São Paulo, 861 p., tese de doutorado, Faculdade de Filosofia, Letras e Ciências Humanas da Universidade de São Paulo.

Barollo, Célia et al. (2007), "Efeito da homeopatia no tratamento de crianças e adolescentes em situação de violência”. Cultura Homeopática, 21 (4): 5-10.

Coelho, Cideli et al. (2014), "Pilot study: evaluation of homeopathic treatment of Escherichia coli infected swine with identification of virulence factors involved". International Journal of High Dilution Research, 49 (4): 197-206.

FIORE, Juliano. (2015), A guerra dos mundos ou as relaçôes institucionais entre a homeopatia e a medicina cientifica. São Paulo, 323 p., tese de doutorado, Faculdade de Filosofia, Letras e Ciências Humanas da Universidade de São Paulo.

Fontes, Olney. (2007), "Janelas para o conhecimento homeopático". Cultura Homeopática, 19 (2): 7-8.

Holandino, Carla \& Kokornaczyk, Maria. (2021), "Editorial: Homeopathy in the treatment of Covid-19”. International Journal of High Dilution Research, 20 (1): 1.

Ikegami, Andréa. (2005), "Abordagem temática de caso clínico". Cultura Homeopática, 11 (2): 13-15.

Lemos, Môsar et al. (2011), "In vitro behavior of Mycoplasmagallisepticum live-type nosode”. International Journal of High Dilution Research, 10 (4): 362-368.

Luz, Madel. (1996), A arte de curar versus a ciência das doenças: história social da homeopatia no Brasil. São Paulo, Dynamis Editorial.

Luz, Madel. (1988), Natural racional social: Razão médica e racionalidade científica moderna. Rio de Janeiro, Editora Campus.

Luz, Madel. (2003), “Entrevista: Dra. Madel Luz, uma visão sociológica da saúde”. Cultura Homeopática, 4 (2): 6-7.

Ministério Da SAÚde. (2015), Politica Nacional de Práticas Integrativas e Complementares - $2^{a}$ edição. Brasília, Ministério da Saúde.

Monteiro, Dalva \& Iriart, Jorge. (ago. 2007), "Homeopatia no Sistema Único de Saúde: representações dos usuários sobre o tratamento homeopático". Cadernos de Saúde Pública, 23 (8): 1903-1912.

Moraes, Adélia (2005), “A clínica da palavra”. Cultura Homeopática, 11 (2): 6-9.

Priven, Silvia \& JuRJ, Gheorghe. (2009). “Signos visuais em homeopatia: Semiótica e cognição”. Revista de Homeopatia, 72 (3-4): 9-14. 
Rosenbaum, Paulo. (2002), “Apresentando a cultura homeopática”. In: Cultura Homeopática, $1(1): 5$.

Rosenbaum, Paulo. (2005), "Ainda a homeopatia ou O que será do fim? (a respeito do editorial do The Lancet)". Cultura Homeopática, 12 (3): 4-5.

Rosenbaum, Paulo \& Priven, Silvia. (2006), “Contribuições à promoção do cuidado”. Cultura Homeopática, 15 (2): 6-10.

Rossi, Fabrício et al. (2006), "Aplicação do medicamento homeopático Carbo vegetabilis e desenvolvimento das mudas de alface”. Cultura Homeopática, 17 (4): 14-17.

SHANG, Aijing et al. (2005), "Are the clinical effects of homoeopathy placebo effects? Comparative study of placebo-controlled trials of homoeopathy and allopathy". The Lancet, 366 (9.487): 726-732, 27 de agosto a 2 de setembro.

Simmel, Georg. (1992), Soziologie: Untersuchungen über die Formen der Vergesellschaftung (Georg Simmel Gesamtausgabe, vol. 11). Frankfurt am Main, Suhrkamp.

Solon, Luiz. (2002), "Contradições sociais da homeopatia: desafios para os homeopatas enquanto sujeitos históricos”. Revista de Homeopatia, 67 (1-4): 47-54.

Solon, Luiz. (2004), "Saúde e sofrimento (pesquisa qualitativa sobre as implicações do tratamento homeopático na saúde de uma criança com retardo mental)”. Revista de Homeopatia, 69 (1-4): 11-20.

Stiefelmann, Henrique. (2011), "Arte homeopática”. Revista de Homeopatia, 74 (4): 31-48.

Triana, Amarilys. (2004), "Semiótica biomédica e seus limites: criando atalhos entre o sutil e o evidente”. Cultura Homeopática, 9 (3): 28-38.

ZACHarias, Carlos. (2007), "Cultura em transição". Cultura Homeopática, 20 (3): 4-5.

\section{Resumo}

A busca por legitimação na cultura homeopática

Este artigo se baseia em uma pesquisa documental sistemática dos principais periódicos de homeopatia em circulação no Brasil entre 2002 a 2015. Embora estejamos em condições de saber que os preparados homeopáticos não passam de placebos, a doutrina homeopática goza de um grau considerável de reconhecimento social e institucional no Brasil. Neste artigo, descrevo e analiso as principais estratégias de legitimação usadas por homeopatas para resguardar a doutrina de críticas da comunidade científica. Identifico e discuto duas estratégias antagônicas, que refletem um conflito interno à cultura homeopática: a abordagem cientificista e a culturalista, esta última de especial interesse, por envolver a instrumentalização dos referenciais teóricos das ciências humanas.

Palavras-chave: Sociologia das ideias; Homeopatia; Medicina complementar e alternativa; Legitimação; Agnotologia. 


\section{Abstract}

\section{The quest for legitimacy in homeopathic culture}

This paper is based upon systematic documentary research on two homeopathic journals circulating in Brazil between 2002 and 2015. Even though we are in a position to know that homeopathic preparations are but placebo pills, the homeopathic doctrine enjoys a considerable degree of social and institutional recognition in Brazil. This paper describes and analyzes the main legitimation strategies homeopaths deploy in order to shield the doctrine from criticisms coming from the scientific community. As a result, I identify and discuss two opposing strategies which reflect a conflict within the homeopathic culture. These are labeled the scientificist and the culturalist approaches, the latter being of particular interest since it entails an instrumentalization of the theoretical framework from the social sciences.

Keywords: Sociology of ideas; Homeopathy; Complementary and alternative medicine; Legitimation; Agnotology.

Texto recebido em 21/06/2021 e aprovado em 24/09/2021.

DOI: $10.11606 / 0103-2070 . t s .2021 .187575$

Lenin Bicudo BÁrbara é pesquisador de pós-doutorado vinculado ao Departamento de Sociologia da FFLCH-USP, com bolsa PNPD/Capes. Formou-se desde a graduação na mesma instituição. No momento, desenvolve pesquisa no âmbito dos estudos da ignorância, com ênfase na circulação da desinformação sobre temas ligados à saúde. Já desenvolveu trabalhos em diálogo com a teoria social, teoria cognitiva, epistemologia, pensamento social alemão, filosofia e história da ciência - especialmente da medicina -; e estudos de gênero. Também atua como tradutor, tendo vertido para o português textos do filósofo e sociólogo alemão Georg Simmel, e do historiador da arte Aby Warburg, entre outros, ainda no prelo. E-mail: leninbicudo@gmail.com. 